\title{
EXPERIMENTAL INVESTIGATION OF PULL OUT STRENGTH OF FLEXIBLE TIES IN THIN BRICK VENEER LAYER
}

\author{
Robertas ZAVALIS ${ }^{*}$ Bronius JONAITIS \\ Department of Reinforced Concrete Structures and Geotechnics, \\ Vilnius Gediminas Technical University, Vilnius, Lithuania
}

Received 9 January 2020; accepted 30 January 2020

\begin{abstract}
The use of thin brick veneer layers for building facades becomes more popular nowadays. Using thin bricks (50-65 mm thick) instead of normal $100-120 \mathrm{~mm}$ thick bricks let us to save expenses up to $50 \%$ related to materials. The connection of thin veneer layer with inner construction wall must be assured. Usually, the connection is fulfilled using flexible metal or composite ties. The main issue for this connection is tie pull out strength from thin brick masonry. This strength depends on type and construction of ties and it governs the number of ties need for facades. This article describes experimental research of pull out strength of flexible steel ties in thin brick masonry. Two possible anchoring types were used. Experimental test results and analysis are described in the article.
\end{abstract}

Keywords: thin brick veneer layer, flexible steel ties, pull out strength.

\section{Introduction}

When building new buildings with layered exterior walls or renovating them, one of the most rational solutions is an establishment of ventilated facade. In this case, an air gap is left between the heat insulating layer and the facade veneer. The air gap allows the humid to be removed from the heat insulating layer and interior surface of facade veneer. The veneer layer is established often from ceramic (most often clinker) bricks, the thickness of which is $95-120 \mathrm{~mm}$. Such veneer layer is durable, resistant to environmental influences, protects the building from overheating during summer. This allows to reduce the energy costs or makes it possible to dispense with room conditioning. By protecting the environment and reducing energy costs for the production of veneer layer materials, there is a tendency to reduce the thickness of the veneer layer of the layered walls. It is proposed to use $65 \mathrm{~mm}$ width ceramic (clinker) bricks for the installation of the veneer layer. In the layered walls, the connection between veneer layer and inner support is fulfilled with flexible ties (Figure 1).

Flexible ties allow layers to freely deform in the wall plane and ensure layer interaction (joint work) out of the wall plane. When the layered walls are exposed to wind load (pressure or suction), flexible ties must transmit it to the inner load bearing wall (Lithuanian Standards Board, 2006). The number of flexible ties depends on acting lateral loads and tie tensile/compressive loadbearing capacity. Flexible ties of various structural solutions are used: perforated steel plates, carbon fibre bars, galvanized or stainless-steel wire (Martins et al., 2017a, 2017b; Reneckis \& LaFave, 2012; Choi \& LaFave, 2004). When thickness of the veneer layer is low $(65 \mathrm{~mm})$, it is expedient to use a flexible tie made of wire (Jonaitis et al., 2017). The simplest

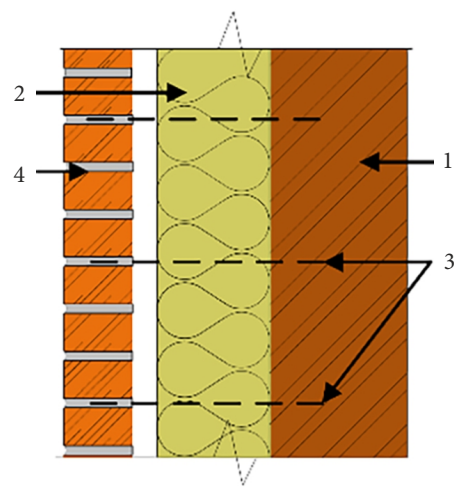

Figure 1. Solution of layered wall: 1 - construction wall, 2 - thermal insulation, 3 - flexible tie, 4 - veneer layer

*Corresponding author. E-mail: robertas.zavalis@vgtu.lt 
a)

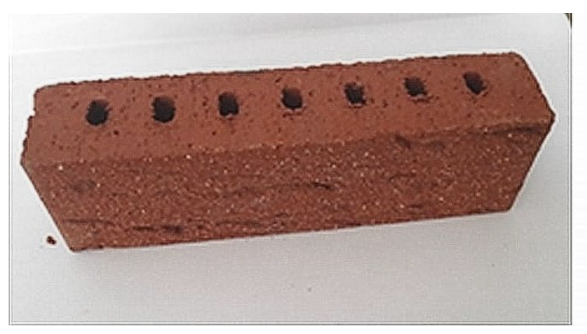

b)

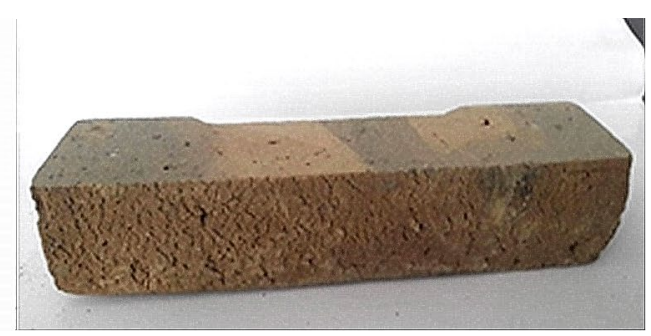

Figure 2. Ceramic veneer bricks: a - perforated (P), b - solid (S)

solution of flexible tie is connection from a $3 \mathrm{~mm}$ diameter galvanized or stainless-steel wire. The tie is screwed into inner support of the wall using a polymer pin. For better adhesion to the finish surface, a bend is made.

When the veneer layer is thin (approximately $65 \mathrm{~mm}$ ), width of mortar bed joint is approximately $60 \mathrm{~mm}$. The flexible ties are placed in the horizontal mortar joint of the masonry veneer layer, leaving a distance of about 30 $\mathrm{mm}$ from the outer surface of the layer. In this case, the load bearing capacity of the flexible tie depends on the tie pull out strength from mortar joint. There is not enough data in the literature on the load bearing capacity of such flexible ties. In most cases, the load bearing capacity of the flexible ties which depends on anchoring of the tie in bed joint is determined by the experiments. a)

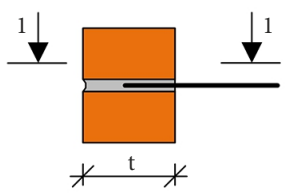

b)

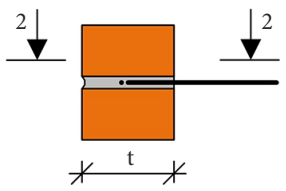

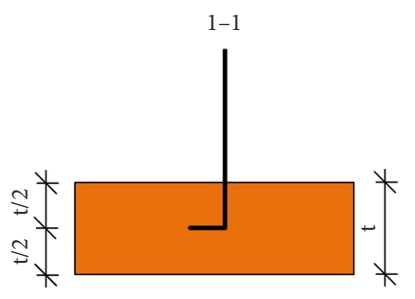

$2-2$

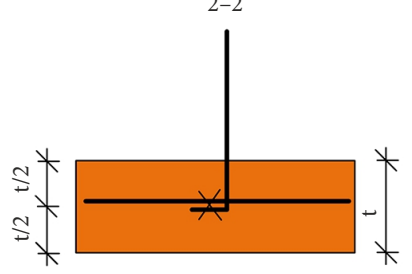

Figure 3. Solutions of flexible tie instalation into the mortar bed joint: $\mathrm{a}-1$ method, $\mathrm{b}-2$ method

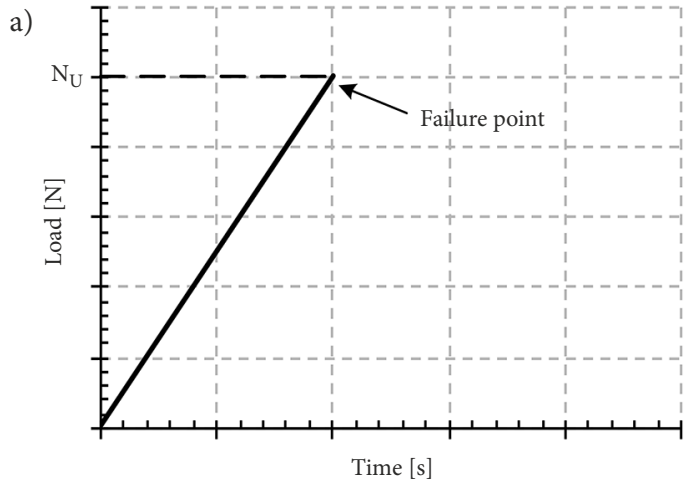

The aim of the article - to determine the load bearing capacity of flexible tie experimentally.

\section{Materials, samples, testing methodology}

To test anchoring of flexible ties two types of ceramic bricks were used: perforated $245 \times 70 \times 53$ and solid $255 \times 58 \times 65 \mathrm{~mm}$ (Figure 2). The horizontal mortar joint is formed using general purpose mortar Weber M100/600 according to LST EN 998-2 (Lithuanian Standards Board, 2017). Flexible ties - $\varnothing 3.9 \mathrm{~mm}$ stainless steel bars with bend, length of bend - $53 \mathrm{~mm}$ (Figure 3). Flexible ties are instaled into bed joints in two ways (Figure 3 ). In the first case, the flexible tie is installed into the masonry bed joint directly (Figure 3a), in the second case, the flexible wire is fixed additionally to the bent part of tie (Figure $3 \mathrm{~b}$ ). Thickness of masonry bed joint $-12-15 \mathrm{~mm}$.

The samples were tested with short-term static load by pulling out the tie from masonry bed joint. Some samples were tested by loading with tensile load in two stages: the tie was loaded by tensile load $\mathrm{N}_{\mathrm{t}}=15 \mathrm{~N}$, after this the load was reduced till $\mathrm{N}_{\mathrm{t}}=10 \mathrm{~N}$. Such load was repeated 5 times, after this the load was increased till failure, i. e. the pull-out strength was estimated (Figure 4). The aim of such load - to estimate influence of load character on load bearing capacity of the anchor (anchoring strength). Such load is characteristic during gusts of wind. Scheme of the test and overall view of the test is shown in Figure 5. Characteristics of the samples and the load character are shown in Table 1.

The samples were compressed by constant load perpendicular to tensile load, in order to imitate masonry

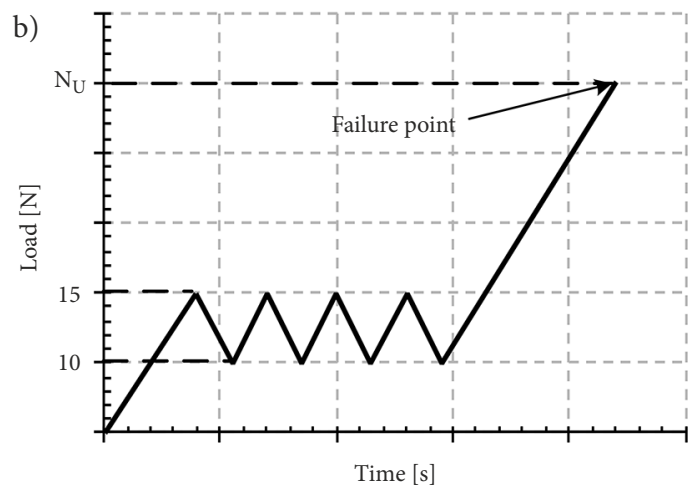

Figure 4. Load character: a - load is increased till failure (1 method); loading in stages ( 2 method) 
Table 1. Characteristics of the samples

\begin{tabular}{|c|c|c|c|c|c|c|}
\hline \multirow{2}{*}{ Series } & \multirow{2}{*}{ Type of bricks } & \multicolumn{2}{|c|}{ Anchoring type } & \multicolumn{2}{|c|}{ Load character } & \multirow{2}{*}{$\begin{array}{l}\text { Mean thickness } \\
\text { of mortar joints }\end{array}$} \\
\hline & & $\begin{array}{c}1 \\
\text { Figure } 3 a\end{array}$ & $\begin{array}{c}2 \\
\text { Figure } 3 b\end{array}$ & $\begin{array}{c}1 \\
\text { Figure 4a }\end{array}$ & $\begin{array}{c}2 \\
\text { Figure } 4 a\end{array}$ & \\
\hline $\mathrm{P} 1$ & \multirow{3}{*}{ Perforated } & + & - & + & - & 13.6 \\
\hline $\mathrm{P} 2$ & & - & + & + & - & 13.2 \\
\hline P3 & & + & - & - & + & 15.6 \\
\hline S1 & \multirow{3}{*}{ Solid } & + & - & + & - & 14.1 \\
\hline S2 & & - & + & + & - & 13.1 \\
\hline S3 & & + & - & - & + & 15.5 \\
\hline
\end{tabular}

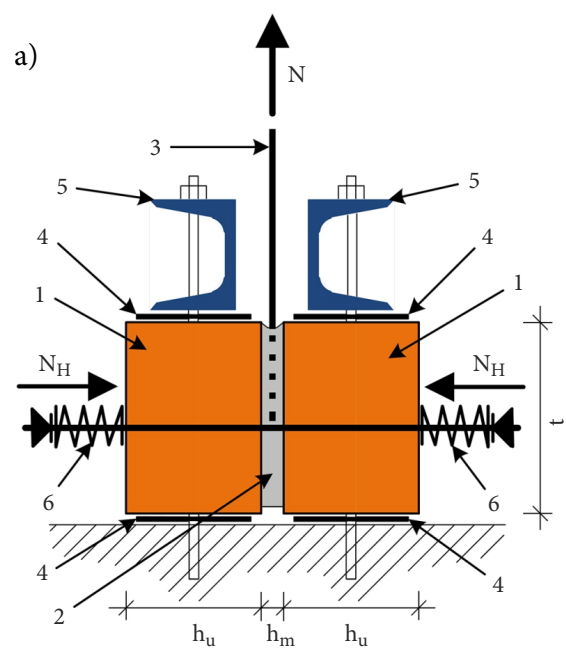

b)

Figure 5. Scheme of the test and overall view: $\mathrm{a}$ - scheme, $\mathrm{b}$ - general view; 1 - ceramic bricks, 2 - mortar joint, 3 - flexible tie, 4 - rubber seam, 5 - frame, 6 - steel rod with springs

bed joint compression by weight of veneer layer in the upper part of the wall evaluating the position of anchors (step in the vertical direction $500 \mathrm{~mm}$ ). It is considered that compressive stresses perpendicular to tensile load are $\sigma_{\mathrm{c}}=10 \mathrm{kPa}$. The samples were tested after hardening of mortar (after 28 days). Bending strength and compressive strength of the mortar were estimated according to the requirements of LST EN 1015-11 standard (Lithuanian Standards Board, 2007). Pul-out deformation of ties was measured during the test.

\section{Materials, samples, testing methodology}

In tests according to LST EN 1015-11 the mean compressive strength of mortar was estimated $\mathrm{f}_{\mathrm{m}}=11.2 \mathrm{MPa}$ (coefficient of variation - 0.05), mean bending strength $\mathrm{f}_{\mathrm{fl}}=2.63 \mathrm{MPa}$ (coefficient of variation - 0.085). Masonry units were tested according to LST EN 772-11 and LST EN 772-21 standards (Lithuanian Standards Board, 2011, 2014). For hollow ceramic bricks the average initial water absorption rate $\mathrm{C}_{\infty \mathrm{s}}=1.82 \mathrm{~kg} /\left(\mathrm{m}^{2} \mathrm{~min}\right)$ (coefficient of variation - 0.057). For solid ceramic bricks the average initial water absorption rate $\mathrm{C}_{\infty \mathrm{s}}=4,15 \mathrm{~kg} /\left(\mathrm{m}^{2} \mathrm{~min}\right.$ ) (coefficient of variation - 0.23 ).

The results of flexible ties test: Pull-out and anchoring strength are presented in Table 2. Anchoring strength of flexible tie according to LST EN 846-5 and EN 846-5(E) (Lithuanian Standards Board, 2012) was estimated according to tensile load, when the deformation of anchor was $5 \mathrm{~mm}$.

Pull-out deformation of tie in tension is shown in Figure 6. The results of the test show that tensile strength of ties depends on mortar bed joint friction in contact with brick. In the diagrams of deformation of ties in tension two stages may be distinguished. In the initial stage deformation increases while tensile load increases. When the tensile load reaches the shear strength of the contact between the mortar joint and the brick, the tensile load decreases and the second stage begins. The deformation increases evenly, but the tensile load does not change.

Table 2. Results of flexible ties test

\begin{tabular}{|c|c|c|c|c|c|c|}
\hline Samples series & P1 & P2 & P3 & S1 & S2 & S3 \\
\hline Mean anchoring strength, $[\mathrm{kN}]$ & 0.44 & 0.4 & 0.256 & 0.28 & 0.3 & 0.26 \\
$(0.11)$ & $(0.065)$ & $(0.34)$ & $(0.37)$ & $(0.17)$ & $(0.41)$ \\
\hline
\end{tabular}

Note: coefficient of variation in brakkets. 

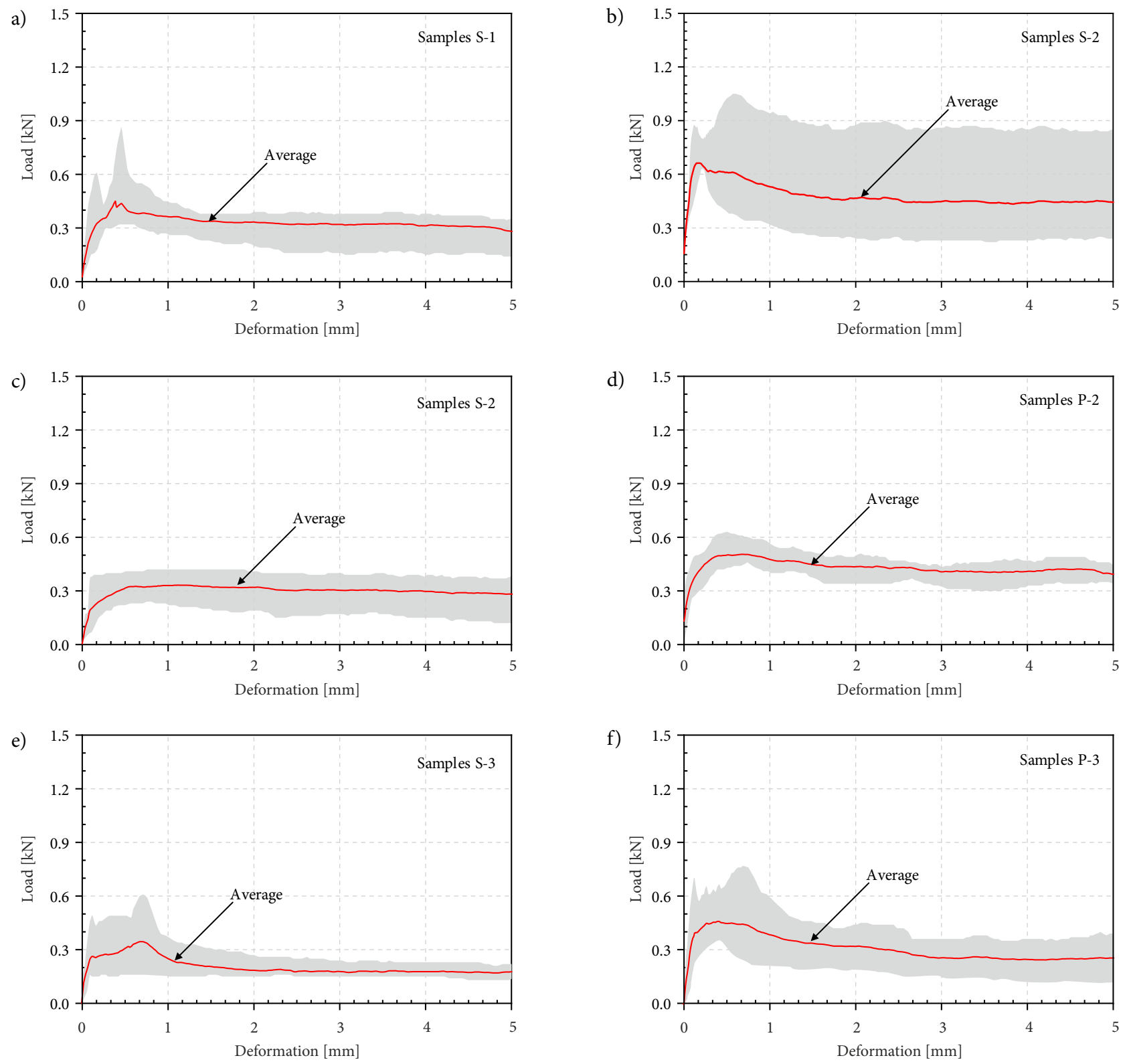

Figure 6. Load - deformation curves of flexible ties in tension: a, c, e - masonry of solid bricks,

$\mathrm{b}, \mathrm{d}, \mathrm{f}$ - masonry of perforated bricks

When the deformation reaches $5 \mathrm{~mm}$, the load bearing capacity of the tie is determined. These two stages are observed in all types of samples.

Anchoring strength differs slightly in samples with solid bricks, in which ties are installed according to the first and the second anchoring method (samples S1 and S2). Anchoring strength differs slightly between samples with perforated bricks and the first and the second anchoring method (samples P1 and P2) as well. It can be argued that the installation of the additional wire rod in the horizontal bed joint did not make and influence on anchoring strength of flexible ties. Additional wire has influence only on the shape of load-deformation curve at the beginning of loading, but almoat no influence to the final anchoring strength (at $5 \mathrm{~mm}$ deformation). The additional bar (the second method of anchoring) in the bed joint changes the character of the sample failure. It can be noticed from the character of mortar failure which is presented in Figure 7.

In comparison of the results of samples with different bricks and the same anchoring methods (samples P1 comparing to S1 and P2 comparing to S2), it can be said that anchoring strength of the samples with perforated bricks is higher up to $54 \%$. The increasing of this strength depends on mortar grooves formed in the hollows of the bricks.

After the cyclic loading of the samples according to the second loading method (S3 and P3), the average anchoring strength of the ties decreased. The biggest decrease (up to $59 \%$ ) was noticed in samples with perforated bricks.

It is necessary to mention that a large scatter of results is characteristic to anchoring strength estimated by experiments with flexible anchors. 
a)

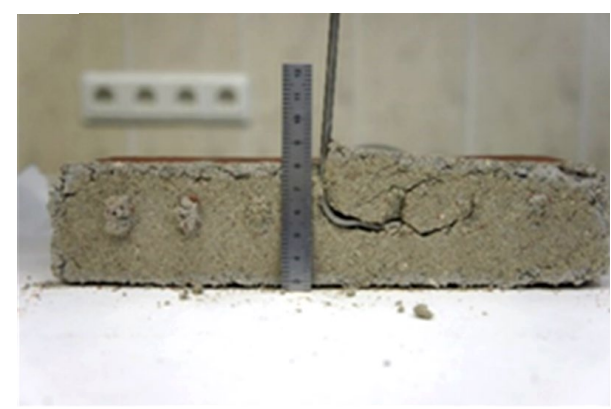

b)

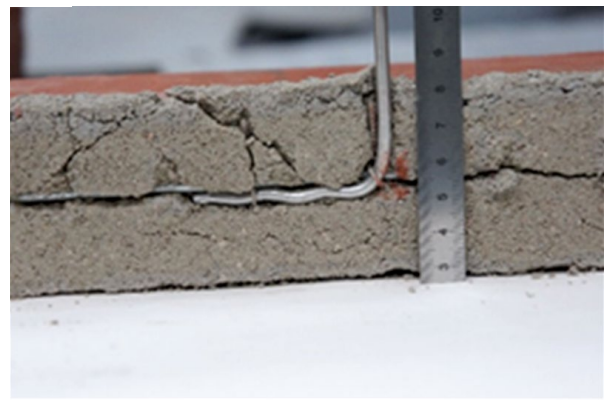

Figure 7. Character of samples failure: $a$ - the first method of anchoring, $b$ - the second method of anchoring

\section{Conclusions}

Studies have shown that the tensile strength of the ties depends on the friction between the mortar and masonry units. The greater anchoring strength of the ties was observed in samples with perforated bricks. Compared to solid brick samples, the anchoring strength increased up to $54 \%$.

The anchoring method of ties in masonry of perforated and solid bricks did not have a significant impact on the anchoring strength. The tests have shown that the cyclic load has a significant effect on the anchoring strength of the ties in perforated brick masonry. Anchoring strength of of ties in solid brick masonry under cyclic loading was insignificant. High coefficient of variation of test results are noticed.

\section{References}

Choi, Y. H., \& LaFave, J. M. (2004). Performance of corrugated metal ties for brick veneer wall systems. Journal of Materials in Civil Engineering, 16(3), 202-211.

https://doi.org/10.1061/(ASCE)0899-1561(2004)16:3(202)

Jonaitis, B., Zavalis, R., \& Oganian, J. (2017). Experimental investigation of the behaviour of brick lintels. Procedia Engineering, 172, 465-472. https://doi.org/10.1016/j.proeng.2017.02.054

Lithuanian Standards Board. (2006). Eurocode 6. Design of masonry structures. General rules for reinforced and unreinforced masonry structures (LST EN 1996-1-1).

http://lsd.lt/index.php?-767145819

Lithuanian Standards Board. (2007). Methods of test for mortar for masonary - Part 11: Determination of flexural and compressive strength of hardened mortar (LST EN 1015-11). http:// lsd.lt/index.php?-1883030193

Lithuanian Standards Board. (2011). Methods of test for masonry units. Determination of water absorption of clay and calcium silicate masonry units by cold water absorption (LST EN 77221). http://www.lsd.lt/index.php?-129382169

Lithuanian Standards Board. (2012). Methods of test for ancillary components for masonry. Determination of tensile and compressive load capacity and load displacement characteristics of wall ties (couplet test) (LST EN 846-5).

http://lsd.lt/index.php?1867442866

Lithuanian Standards Board. (2014). Methods of test for masonry units. Determination of water absorption of aggregate concrete, autoclaved aerated concrete, manufactured stone and natural stone masonry units due to capillary action and the initial rate of water absorption of clay masonry units (LST EN 772-11). http://www.lsd.lt/index.php?-1877331342

Lithuanian Standards Board. (2017). Specification for mortar for masonry. Masonry mortar (LST EN 998-2).

http://www.lsd.lt/index.php?878455058

Martins, A., Vasconcelos, G., \& Costa, A. C. (2017a). Experimental assessment of the mechanical behaviour of ties on brick veneers anchored to brick masonry infills. Construction and Building Materials, 156, 515-531.

https://doi.org/10.1016/j.conbuildmat.2017.09.013

Martins, A., Vasconcelos, G., \& Costa, A. C. (2017b). Brick masonry veneer walls: an overview. Journal of Building Engineering, 9, 29-41. https://doi.org/10.1016/j.jobe.2016.11.005

Reneckis, D., \& LaFave, J. M. (2012). Out-of-plane seismic performance and fragility analysis of anchored brick veneer. Structural Safety, 35, 1-17.

https://doi.org/10.1016/j.strusafe.2011.10.003 